\title{
Arbor
}

\section{El poder aéreo, instrumento decisivo para la resolución de las crisis del siglo XXI}

Juan Antonio Lombo López

Arbor CLXXI, 674 (Febrero 2002), 213-257 pp.

Aquí, su autor, el antiguo Jefe del estado Mayor del Aire (1997-2001), desarrolla de forma clara las características fundamentales del Poder Aéreo, sus cometidos y misiones principales y ciertas consideraciones en el empleo del mismo.

Para ello, se da a conocer el papel que desempeña el Poder Aéreo como componente estratégico principal de la acción de los Ejércitos, estudiando los aspectos claves, político, estratégico y operativo de cualquier campaña militar, así como las características fundamentales, cometidos y misiones más usuales del Poder Aéreo.

Todo lo anterior desde la óptica del puesto en el que le ha tocado vivir las actuaciones del Poder Aéreo en los últimos años, le lleva a la conclusión de que éste es un instrumento sumamente flexible y rentable para su utilización en cualquier tipo de crisis, desde las acciones humanitarias hasta los conflictos abiertos.

\section{Introducción}

Desde su aparición en la Tierra, el hombre había estado limitado a vivir en un espacio de dos dimensiones del que siempre quiso escapar. Durante milenios, ha mirado hacia arriba con ansia y nostalgia. Envidiaba el vuelo de las aves, su capacidad de salvar obstáculos de penosa o im- 
posible superación por el hombre. Barrancos, arroyos, pantanos, ríos, lagos, mares, montañas, cordilleras, bosques, hielos, glaciares y desiertos, intransitables para el hombre, eran natural y grácilmente sobrevolados por las aves, a la vista de una humanidad atada al suelo.

Asimismo soñaba con emular a las aves en el dominio de la altura, mientras buscaba sobre la tierra puntos altos de observación, montañas, colinas, atalayas desde las que incrementar su capacidad de observación de lo que ocurre en esa superficie en la que estaba obligado a vivir, pero que sólo podía ver en un horizonte reducido, pequeños pedazos de su mundo a pequeñas distancias fuera de las cuales podían estar ocurriendo, sin que él lo supiera, cosas que afectaran a su seguridad, su bienestar $u$ otros aspectos de su vida.

El aire no es un medio natural para el ser humano, y el espacio no lo es para ningún ser vivo sobre la tierra. Las leyes de la Física habían establecido dónde podían respirar, qué presión y temperatura podían soportar y hasta dónde podían vencer a la gravedad. ¿Podría el hombre alguna vez oponerse a la física y superar sus inexorables condicionamientos?

La humanidad, empujada por el ansia innata de dominar el mundo que el Creador infundió en su espíritu, se esforzó siempre en alejar las fronteras de sus limitaciones mediante el avance de la ciencia, que le permite conocer mejor la realidad que le rodea en el universo y utilizar ese conocimiento en beneficio propio. Con empeño, coraje y decisión, superando miedos y tabúes, y tras muchos intentos y fracasos, el hombre logró poner alas a sus sueños. Y voló. Voló oponiendo la física a la física, enfrentando las leyes de la aerodinámica a las leyes de la gravitación universal. Y alcanzó el dominio de la tercera dimensión.

El logro de ese dominio ha sido uno de los principales factores que impulsaron los profundos cambios sociales, tecnológicos, económicos, estratégicos y políticos que han transformado la vida de la humanidad en menos de un siglo. Todavía viven personas que en su juventud no podían concebir que llegarían a viajar a Tailandia en unas horas, que podrían regalar flores cultivadas en Colombia o ir a una comida de negocios en Berlín y cenar en Madrid. O que se podría detectar un gran banco de peces, yacimientos minerales, tormentas o inundaciones desde un satélite, y más cuando podían jurar que en el cielo no había más satélite que la Luna y similares. O que, gracias a otro satélite, podrían ver en casa la final del campeonato del mundo que se juega en Tokio y hablar con un amigo que está allí con su equipo. $\mathrm{O}$ que se pudiera ganar una guerra sin perder un solo combatiente ni tener que conquistar un territorio. 
El poder aéreo, instrumento decisivo...

\section{Concepto del Poder Aéreo}

Como era de esperar, la conquista de la tercera dimensión originó una completa revolución en los conceptos políticos, estratégicos y tácticos que rigen la guerra y las operaciones militares, a pesar de que llamaran visionarios a los que se atrevieron a predecirlo, y de que aún haya voces que discuten sus virtualidades en la resolución de crisis o conflictos bélicos.

La función crea el órgano y, para dar respuesta a esos nuevos conceptos, se constituye el Poder Aéreo, instrumento idóneo para aprovechar los beneficios que ofrece el dominio de la tercera dimensión. Su rápida evolución tecnológica multiplica cada día sus posibilidades, y va dejando anticuadas las definiciones y reglas de empleo, incluso las más recientes. Hasta su propia denominación resulta hoy impropia, pues en realidad habría que hablar de poder aeroespacial, aunque lo más común es utilizar todavía hoy el término Poder Aéreo.

EURAC, foro que agrupa a los jefes aéreos de 17 naciones europeas, define el Poder Aéreo como «la capacidad de proyectar Fuerza militar en el aire o el espacio o desde una plataforma o misil que opere por encima de la tierra». En esta definición, debe entenderse como Fuerza militar toda capacidad militar dedicada tanto a misiones ofensivas o defensivas como a cualquier otra no destructiva, como el reconocimiento o el transporte aéreos. Se entiende como plataforma aérea cualquier avión, helicóptero, vehículo aéreo no tripulado, satélite o nave espacial.

El Poder Aéreo no está constituido sólo por las Fuerzas Aéreas, sino que incluye las capacidades aerospaciales que puedan estar asignadas a Fuerzas Terrestres o Navales y, en determinadas circunstancias, la aviación civil y la industria aeronáutica.

Finalmente, el Poder Aéreo no sólo está compuesto por sistemas de armas, sino que son parte esencial del mismo el personal que los emplea, la estructura de mando y control, la infraestructura desde la que opera y el sistema logístico que los mantiene en estado operativo.

\section{Visión estratégica del Poder Aéreo}

La capacidad intrínseca del Poder Aéreo de alcanzar y neutralizar o destruir el centro de gravedad del oponente y los componentes esenciales de su dispositivo, determina su valor estratégico. De ahí que su empleo más rentable es la acción estratégica: romper la cohesión del enemigo, anular o reducir su capacidad de combate, quebrar su resistencia. Por 
ello, más que a destruir el material bélico o las tropas, debe aplicarse contra los intereses vitales del adversario.

Gracias al Poder Aéreo, para anular la capacidad de combate de una división de carros blindados, es más fácil, económico y rentable destruir sus reservas de combustible o los puentes por donde llegan su munición y aprovisionamiento que atacar los tanques uno a uno. Igualmente, para quebrar la resistencia de una población, es más efectivo dejarla sin energía eléctrica, comunicaciones y líneas de aprovisionamiento que producirle bajas.

Llegamos así a un concepto clave donde concurren los aspectos políticos, estratégicos y operativos de una campaña: la selección de objetivos. Se trata de determinar los objetivos físicos cuya destrucción o neutralización puede determinar la consecución de los objetivos de cada fase de la campaña, así como la secuencia y ritmo de los ataques.

A partir de los datos de inteligencia disponibles, se analizan los elementos físicos (edificios, pistas, vías de comunicación, depósitos, etc) que han sido identificados como parte de los sistemas más vitales del oponente (maquinaria gubernamental, fuerzas militares, elementos de producción, infraestructuras de transporte, fuentes de energía, etc). Se determinan los requerimientos y medios para su neutralización, teniendo en cuenta su configuración física, situación, protección antiaérea, posibilidad de daños colaterales y cuantos datos sirvan para fundamentar la decisión.

Esta decisión corresponde al mando político, y es la parte medular de la campaña, ya que puede determinar el éxito o el fracaso de la misma y su coste en vidas humanas y recursos materiales. Naturalmente el proceso ha sido preparado antes de iniciar la campaña aérea, pero va siendo actualizado a la vista de su evolución, tanto en el aspecto político como en el militar. En la actualidad, otro factor relevante que determina el proceso de selección de blancos es la evolución de la opinión pública, muy sensible a lo que le llega a través de los medios audiovisuales.

Felizmente, la flexibilidad del Poder Aéreo ofrece al mando político un instrumento ideal para enfrentar situaciones de incertidumbre o peligro, ya que su capacidad de control sobre la acción aérea es absoluta, toda vez que ésta puede ser activada, detenida, intensificada, ralentizada o reorientada a distintos blancos de manera casi instantánea, hasta el momento mismo de lanzar el armamento y a la vista de lo que está pasando en tiempo real. Y en el caso de que se decidiera la suspensión o el fin de las hostilidades para dar paso a la acción política, no existe el riesgo de encontrarse copados o en situación de difícil retirada, dada la $l i$ bertad de acción que proporciona actuar desde fuera de la zona de conflicto, sin el hostigamiento de fuerzas enemigas. 
El poder aéreo, instrumento decisivo...

Asimismo, el mando político puede aplicar en todo momento criterios de proporcionalidad en función de consideraciones políticas, ordenando o no el ataque a determinado tipo de blancos, limitando el uso de algún armamento o acciones, o imponiendo «reglas de enganche» que determinan normas y limitaciones de empleo, incluyendo el comportamiento de los comandantes, e incluso de los pilotos, ante determinadas amenazas, riesgos propios o de daños colaterales, o ante cualquier situación de incertidumbre.

No escapará al lector la objeción de que el pleno uso de las capacidades estratégicas del Poder Aéreo puede quedar limitado por su vulnerabilidad frente a la acción del oponente, en particular de su Poder Aéreo. Nada más cierto, ya que en principio goza de las mismas características que el nuestro. El libre empleo del Poder Aéreo exige conseguir la «supremacía aérea» (capacidad de operar libremente en todo momento, que exige la anulación de la amenaza aérea y antiaérea contraria), o al menos la «superioridad aérea» (capacidad de operar libremente en un momento y lugar determinados, en los que hay que contrarrestar dicha amenaza).

El concepto de superioridad aérea, que aparece como una situación táctica, adquiere una indudable dimensión estratégica si, mucho antes del conflicto, se ha optado por configurar un Poder Aéreo superior tecnológica y operativamente al de los posibles adversarios. Una decisión estratégica que garantiza al país o coalición que la lleva a cabo una capacidad política y una libertad de acción tanto mayor cuanto mayor sea dicha superioridad, al permitirle disponer de un instrumento para responder de manera rápida y flexible a un amplio abanico de tareas, desde las acciones humanitarias hasta las operaciones ofensivas de largo alcance. Durante la paz, mediante el apoyo a la política exterior en misiones de paz o desastres, y en crisis o guerra, mediante acciones aéreas para mantener los intereses del país o coalición e imponer la paz.

Así se ha podido constatar en innumerables misiones de paz y ayuda humanitaria, que hubieran sido imposibles sin contar con el Poder Aéreo. Lo mismo podemos decir de los últimos conflictos. En el Golfo (1991), el Poder Aéreo posibilitó una ocupación terrestre rápida y con pocas bajas. En Kosovo (1999), por primera vez en la Historia, el Poder Aéreo consiguió por sí solo una verdadera victoria y la imposición de las condiciones de paz de la coalición, sin necesidad de operaciones terrestres y isin una sola baja propia! (En el momento en que se escribe este artículo, se inicia el ataque aéreo a Afganistán, por lo que no cabe juicio sobre el mismo).

Queda por decir que el empleo estratégico del Poder Aéreo tiene su mejor aplicación en el campo de la acción conjunta y combinada, única forma de actuación posible de las Fuerzas militares en el siglo XXI, ya 
que utiliza todas las virtualidades de los medios aéreos, terrestres y navales para una más amplia capacidad de acción en situaciones de crisis o conflicto. Es evidente que el Poder Aéreo no puede acometer por sí solo tareas como la ocupación del territorio, el control del mar, interposición de fuerzas, contraterrorismo y otras operaciones de mantenimiento de la paz o prevención de conflictos. Al mismo tiempo, no se conciben operaciones militares en superficie sin un cierto grado de superioridad aérea, sin apoyo aéreo cercano, sin inteligencia aeroespacial o sin transporte aéreo estratégico y táctico. De ahí la necesidad de un planeamiento conjunto y una acción conjunta equilibrada.

Actuar conjuntamente significa que bajo dirección única, cada Fuerza ejecuta la parte de la misión que se le asigna, coordinadas en tiempo, lugar e intensidad por el mando supremo, al igual que en una orquesta, en la que el director ejecuta la partitura asignando a cada profesor la parte de su instrumento y coordinando entradas, silencios, cadencias, tempo y ritmo, para que el conjunto resulte armonioso y, si la partitura exige un solista, le da protagonismo y un cierto grado de libertad, mientras el resto de los instrumentos le apoyan coordinadamente.

De ahí que la acción conjunta no consista en crear nuevas estructuras o en amalgamar las terrestres, navales y aéreas en una sola, con riesgo cierto de perder el dominio de las capacidades y formas propias de acción de cada Ejército que, para ser eficaces, exigen mentalidades diferentes, formación diferente, organización diferente y entrenamiento diferente. Lo lógico es sacar el mayor rendimiento de las estructuras existentes, que en cualquier caso son indispensables. El mando supremo utilizará en cada operación los órganos de mando y control de la Fuerza más capacitada para la misma, la cual será apoyada por las otras y tendrá el protagonismo que se le asigne. Esta es la tendencia que se va imponiendo, ya que une a su simplicidad, eficacia y sentido práctico una notable economía de recursos, en particular de personal especializado, escaso y valioso.

\section{Características fundamentales del Poder Aéreo}

En el esquema bosquejado, destacan tres características intrínsecas del Poder Aéreo:

\section{Dominio de la tercera dimensión}

La posibilidad de operar en una gama de alturas desde el vuelo a muy baja cota hasta la órbita geoestacionaria, da al Poder Aéreo la facultad 
El poder aéreo, instrumento decisivo...

de observar con precisión lo que ocurre tanto en el aire-espacio como en la superficie de la Tierra y disponer de esa información en tiempo real. Las ventajas militares de una perspectiva global y detallada del campo de batalla, conteniendo toda la realidad que le incumbe, son definitivas para el Mando en el momento de tomar decisiones y para las Fuerzas en el momento de la acción. Saber es poder.

Asimismo, el dominio de la altura permite llegar a cualquier lugar obviando los obstáculos del terreno o las costas, y operar desde el aire dominando cualquier objetivo.

\section{Velocidad}

Intrínseca de los sistemas aerospaciales, supone el control de la variable tiempo. Permite desplegar, proyectar y operar Fuerzas en tiempos mínimos. Al completar las misiones más rápidamente, los mismos medios pueden reutilizarse varias veces en un período dado, lo que significa actuar más intensamente o cumplir más misiones en más sitios y en menos tiempo. De hecho, el mismo avión puede atacar un puesto de mando por la mañana, hacer un reconocimiento aéreo a mediodía y una misión de defensa aérea por la noche, y todo a distancias de $1.000 \mathrm{Km}$. de su Base. El Poder Aéreo puede «estar allí» cuando hace falta.

\section{Alcance}

Los sistemas aéreos pueden volar largas distancias (aviones B2 despegaron desde EE.UU., bombardearon en Kosovo con precisión de metros y aterrizaron sin escalas en EE.UU.). Sobrevuelan océanos en horas, grandes cordilleras en minutos, ríos o barrancos insalvables en segundos. No se detienen ante las costas, ni ante la noche, ni ante el frío, el calor, la nieve o el desierto. Sin cambiar de Base, actúan en cualquier dirección; ir al Norte o al Sur es cuestión de un viraje de veinte segundos. Pueden obviar las defensas oponentes y «colarse» hasta el corazón del contrario. Nada queda fuera de su alcance ni puede considerarse a salvo.

Un juicioso uso de las características enunciadas, ofrece capacidades militares que no estaban a nuestro alcance y que eran inconcebibles antes de la existencia del Poder Aéreo. Pero esas capacidades, por muy deslumbrantes que parezcan, resultarían sólo un caro juguete si no dieran respuesta a las necesidades que surgen de las amenazas que deban afrontarse en los tiempos que se avecinan. 


\section{La amenaza a afrontar en la actual situación estratégica}

Tras la caída del telón de acero y el final de la guerra fría, ha desaparecido la terrible «amenaza roja», el riesgo de holocausto nuclear que hacía temer la destrucción del planeta. Pero ha aparecido la «amenaza gris», menos apocalíptica, menos definida, más difusa, pero más probable que la anterior. Puede surgir en cualquier lugar del mundo. Va desde el conflicto tribal hasta la guerra abierta, pasando por todas las variedades de guerras civiles, genocidios y desastres humanitarios. A ello hay que unir la amenaza de un terrorismo rampante y globalizado, una hidra de mil cabezas que puede morder mortalmente en cualquier lugar, impulsado por un mismo sentimiento de odio fanático y alimentado por intereses poderosos.

Siempre han existido grupos extremistas o naciones escasamente vertebradas, cargados de fundamentalismo nacionalista, ideológico o religioso mezclado con intereses económicos y ansias de poder, que no han dudado en agredir a las sociedades a las que pertenecen o a las naciones próximas para tratar de someterlas o imponerles sus dictados por la fuerza. El daño que infringían tenía una repercusión local o regional, por lo limitado de sus capacidades y área de influencia. La responsabilidad de combatirlo era local o regional.

Pero en el mundo globalizado en que vivimos, aunque en muchos casos la amenaza brote en conflictos locales, el riesgo de rápida extensión y contagio es global y puede originar grandes catástrofes. El desarrollo económico, social y tecnológico de la humanidad, que ha estimulado el bienestar, la seguridad y la libertad, puede ser usado en contra de la misma libertad. La difusión de la tecnología, el libre comercio (que incluye los medios de destrucción), la facilidad de comunicaciones, la libertad de movimientos y todas las garantías legales que protegen hoy las libertades, pueden ser usados también con fines agresivos, incluso por grupos poco desarrollados. Las repercusiones de las agresiones traspasan los límites locales y regionales, nadie puede considerarse seguro. La responsabilidad de combatirlas puede alcanzar a todos.

Hoy hay naciones políticamente inestables que poseen o están en condiciones de alcanzar cierta capacidad de ataque nuclear. Medios de destrucción masiva, química y bacteriológica, resultan de relativamente fácil obtención. Grupos reducidos, sin necesidad de grandes recursos, pueden llevar a cabo acciones terroristas en el medio urbano que pueden tener trágicas repercusiones. Un genocidio originado por un delirio nacionalista, puede desarrollarse ante los ojos asombrados del mundo y extenderse alrededor. Recursos necesarios para el desarrollo económico 
El poder aéreo, instrumento decisivo...

mundial, pueden ser amenazados por afanes expansionistas o de dominio. Apuntan otros posibles conflictos por las migraciones masivas, el tráfico de drogas o el control de los recursos esenciales, tan importantes como el agua.

De la verosimilitud de estas nuevas amenazas es ejemplo paradigmático el ataque terrorista en Nueva York y Washington del 11 de septiembre pasado, cuyas consecuencias, en el momento de escribir este artículo, no son previsibles. Otros ejemplos no han faltado en los últimos años, genocidios, luchas tribales extraordinariamente crueles, disputas territoriales de todo tipo, invasiones de países vecinos, agresiones terroristas enmascaradas en delirios nacionalistas o fundamentalismos religiosos, y actividades guerrilleras apoyadas en negocios de droga, han aparecido en toda la superficie del planeta de manera más o menos virulenta y repentina.

Frente a esta nuevas amenazas, se requieren unas respuestas políticas a medio y largo plazo que extiendan el ámbito de las sociedades libres, desarrolladas y equilibradas. Medidas tan imprescindibles como de difícil y lenta implantación. Pero, simultáneamente, es necesario garantizar la paz, la seguridad y la libertad, lo que exige disponer de un dispositivo militar que evite o neutralice agresiones caracterizadas por su imprevisibilidad, ya que pueden aparecer en cualquier lugar, en cualquier momento, con cualquier intensidad, revistiendo muy variadas formas de agresión y con repercusiones imprevisibles, pero seguras, en otras zonas del mundo.

Con esos datos, el dispositivo militar resultante tiene que ser polivalente. Debe ser capaz de evitar el estallido del conflicto mediante la disuasión. Si el conflicto se inicia, debe ser capaz de responder rápidamente, en cualquier lugar, afrontando una gran variedad de agresiones con contundencia proporcionada a la amenaza. Durante el conflicto debe ser capaz de adaptarse a la evolución del mismo, lo que significa graduar la intensidad de su actuación desde el simple estado de alerta hasta los ataques en fuerza, pasando por la ayuda humanitaria, lo que exigirá acometer distintos objetivos, emplear distintos medios y grados de respuesta, y modificar despliegues, manteniendo en todo momento la seguridad propia. Tras imponer la paz debe ser capaz de apoyar las medidas políticas, garantizar la seguridad de la población y evitar el rebrote de las agresiones. En todo momento debe ser capaz de mantener actualizada la información necesaria para la toma de decisiones y el desarrollo de las operaciones. Todo ello, además de la voluntad de vencer y acción conjunta necesarias a toda fuerza armada, significa flexibilidad, movilidad y superioridad tecnológica y operativa. 


\section{Capacidades fundamentales del Poder Aéreo}

Felizmente, las características del Poder Aéreo enunciadas más arriba, dan lugar a ciertas capacidades militares idóneas para hacer frente a la amenaza perceptible en la actual situación geoestratégica.

\section{Rapidez de reacción}

La rapidez de reacción es clave en cualquier situación que exija la intervención militar, ya sea en combate, acciones humanitarias, apoyo de la paz u operaciones de rescate. La rapidez con que el Poder Aéreo puede ser desplegado y empleado, lo convierte en un instrumento particularmente útil para la gestión política de situaciones de crisis. Su capacidad de reacción va desde una situación de alerta en sus Bases de paz (reacción en días), a otra en despliegue avanzado (reacción en horas) o en alerta en el aire (reacción en minutos).

La operación «Deliberate Falcon» fue uno de los muchos intentos para resolver el conflicto de Kosovo por medios políticos y evitar una confrontación armada. En una demostración de fuerza que intentó, lamentablemente sin éxito, convencer al Mando servio del riesgo que corría si persistía en su actitud hostil, se concentraron cerca de trescientos aviones en el espacio aéreo circundante, sobrevolándolo durante varias horas con toda su capacidad ofensiva. Dichos aviones partieron de sus Bases de paz, desde las diversas naciones, y fueron puestos en alerta menos de cuarenta y ocho horas antes.

Un ejemplo de la rapidez de reacción desde despliegue avanzado es el dispositivo permanente de alerta y reacción rápida de defensa aérea, que mantiene en todos los países de la Alianza Atlántica, en distintas bases, veinticuatro horas al día, trescientos sesenta y cinco días al año, un cierto número de aviones listos para estar en el aire entre cinco y quince minutos después de que se haya detectado la necesidad de su intervención, ya sea para ayudar a un avión civil en emergencia, para obligar a aterrizar a un avión cuyo sobrevuelo no esté autorizado o para derribar a un avión hostil que pueda atacar un objetivo en nuestro territorio o reaccione agresivamente. Tan notable capacidad es rutina para el Poder Aéreo desde hace muchos años.

Una capacidad de reacción más avanzada se obtiene con la alerta en el aire. Aviones en vuelo pueden realizar acciones de defensa o ataque en el instante de recibir la orden. Tanto en la guerra del Golfo como en la de Kosovo se utilizó este dispositivo para contrarrestar las acciones iraquíes o ser- 
El poder aéreo, instrumento decisivo...

bias contra las fuerzas de la coalición, ya fuera en el aire o en tierra. También se utiliza en paz cuando se presume un ataque o agresión inmediata.

Para adaptarse a cualquier modificación en la situación política o militar, el Poder Aéreo puede cambiar inmediatamente su dispositivo, lo que lo convierte en instrumento idóneo para la gestión de crisis o para la desescalada de las mismas, ya que puede ser desplegado, empleado en diferentes formas o grados de intensidad, o retirado con gran rapidez y mínimo riesgo.

\section{Flexibilidad}

Otra capacidad del Poder Aéreo que responde en alto grado a las necesidades en crisis o guerra es su flexibilidad. Puede ser empleado en el completo espectro de las operaciones militares, desde las misiones humanitarias hasta los conflictos armados. En el ámbito humanitario realizando evacuaciones de las zonas de peligro, evacuaciones médicas, acciones de rescate, salvamento y transporte de alimentos, medicinas, personal especializado o cualquier otro recurso vital en situaciones de catástrofe humanitaria. En los conflictos armados, proporcionando desde el aire-espacio inteligencia vital para la toma de decisiones y realización de operaciones, transportando fuerzas terrestres a, o desde sus posiciones de combate, alimentando logísticamente las operaciones, defendiendo desde el aire las fuerzas propias mediante la superioridad aérea $o$ atacando objetivos enemigos.

Puede ser utilizado contra objetivos a nivel estratégico, operativo o táctico. En toda clase de entornos geográficos, hielos, mares, desiertos, selvas, montañas y llanuras; de día, de noche y en todo tiempo. No necesita operar desde dentro del área de operaciones, por lo que no está sujeto a hostigamiento y, por ello, detener, retirar o redesplegar los medios aéreos para otra operación no exige una arriesgada y complicada retirada.

A nivel táctico, la capacidad de los aviones «multi-role»o polivalentes, proporciona un instrumento sumamente flexible y económico, al ser aplicable a un gran abanico de misiones, defensivas u ofensivas, mediante un simple cambio de configuración de armamento, normalmente en menos de una hora. Así el mismo avión puede realizar en el mismo día misiones de defensa aérea, reconocimiento, antibuque, supresión de defensas aéreas, ataque estratégico, apoyo táctico cercano o patrulla de combate en busca de objetivos de oportunidad. $\mathrm{E}$ incluso los aviones «swing-role» o de doble misión pueden realizar más de una misión en la misma salida, al llevar armamento y equipo válido para ello. Durante la guerra del Golfo, hubo aviones F-18 que bombardearon objetivos terrestres en Irak tras haber derribado aviones iraquíes con misiles aire-aire mientras volaban hacia los mismos. 
En cuanto a la flexibilidad de los medios de transporte aéreo, podemos decir por ejemplo que los aviones CASA 235 del Ala 35 de la Base Aérea de Getafe, pueden cambiar en menos de una hora su configuración de transporte de carga a pasajeros, transporte VIP, búsqueda y salvamento, transporte táctico, lanzamiento de paracaidistas o carga, transporte de órganos para trasplantes, aeroevacuación de enfermos y heridos o UVI aérea. Y así configurados, pueden operar en misiones de guerra o humanitarias en cualquier dirección en un radio de acción del orden de los $3.000 \mathrm{Km}$.

\section{Capacidad de multirrespuesta}

Como consecuencia de su velocidad, alcance y flexibilidad, el Poder Aéreo supone una considerable capacidad de multirrespuesta. Puede simultáneamente desde sus propias Bases ejercer la disuasión sobre diversas amenazas situadas en diferentes áreas geográficas, ejerciendo su influencia al amenazar las diferentes opciones estratégicas del oponente, y hacer efectiva su presencia en cualquier momento y en cualquier lugar.

\section{Precisión}

Aunque no es intrínseca del Poder Aéreo, la tecnología asociada al mismo ofrece hoy una capacidad del más alto valor, la precisión. La relativamente reciente disponibilidad de armamento extraordinariamente preciso, tan preciso como para poder seleccionar no sólo el objetivo sobre el que debe caer el arma, sino la ventana por donde debe entrar y el piso en el que debe estallar, ha multiplicado la capacidad del Poder Aéreo y ha hecho su empleo más acorde con los fines politicos en la resolución de crisis.

Dicha precisión combinada con el dominio de la tercera dimensión y el alcance, permite neutralizar o destruir el centro de gravedad del dispositivo enemigo con medios proporcionados. Se han superado los terribles bombardeos de saturación que durante la $2^{\text {a }}$ Guerra Mundial destruían ciudades enteras para batir objetivos de tamaño relativamente reducido, y hoy no se piensa en armas nucleares de destrucción masiva. Citaremos un ejemplo real de la última guerra mundial: para destruir un objetivo de 60 metros x 50 se consideró necesario conseguir un mínimo de 2 impactos directos; para asegurarlos, se llevó a cabo un bombardeo con 108 aviones B-17 (Fortalezas volantes), tripuladas por 1.080 hombres, que lanzaron 608 bombas. Hoy lo conseguiríamos con un avión tripulado por un solo piloto que lanzaría dos bombas. Naturalmente, eso exige haber alcanzado la superioridad aérea. Conseguida ésta, fuerzas más redu- 
cidas pueden conseguir efectos que sin ella serían imposibles o tendrían un coste enorme en vidas humanas y recursos materiales.

Otra baza política que apoya la precisión del armamento aéreo, es la de reducir los daños colaterales de los ataques. En la gestión de crisis tal como se contempla hoy, se considera indispensable evitar infringir graves daños a la población, lo cual puede lograrse con el uso de armamento de precisión. En la guerra del Golfo, la proporción de armamento guiado que se utilizó estuvo en torno al 15\%. En Kosovo estuvo en torno al $85 \%$, lo que denota una clara tendencia.

Paradójicamente, esta espectacular capacidad ha llevado a ciertos medios a criticar cualquier daño colateral, como si se pudiese alcanzar el daño cero. Eso nunca será posible, pues un cierto grado de error en la información, imprevisión en el planeamiento o fallo de percepción en la ejecución, es propio de seres humanos, y más cuando están sometidos a tensión y tienen que tomar decisiones en medio de gran incertidumbre.

Es verdad que hay víctimas inocentes. Pero cuando el objetivo es garantizar la paz y la libertad a poblaciones enteras, amenazadas de un riesgo cierto de sometimiento o genocidio, el problema está en elegir entre las alternativas de que se dispone, no entre las que no están a nuestro alcance ni entre las que no sirven. Siempre es preferible la política a la guerra, pero cuando los intentos políticos de evitar con infinita paciencia una intervención militar fracasan, entra en consideración el hecho de que la pasividad ante la violencia engendra más violencia entre quienes sólo ceden ante la violencia, y la historia nos muestra como la transigencia ante la agresión no suele detenerla, sino que la agrava. La sentencia popular dice que si se quiere comer tortilla hay que romper huevos. Cuando el uso de la fuerza se hace indispensable, el empleo del Poder Aéreo con armamento de precisión hace mínimos los daños colaterales y las víctimas. La paz en Kosovo y la vuelta de los albaneses a sus hogares de los que habían sido expulsados, se logró sin bajas propias y en torno a 500 bajas civiles. Cualquier otra intervención en fuerza por tierra hubiera costado miles de bajas en ambos lados.

\section{Movilidad}

La movilidad inherente del Poder Aéreo, consecuencia de la velocidad y dominio de la altura, alcanza una capacidad no igualable con ningún otro medio. Le permite operar prácticamente en cualquier sitio desde cualquier otro. Además de su movilidad propia, incrementa la movilidad de fuerzas terrestres mediante el transporte aéreo de tropas, material, armamento y avituallamiento a las zonas de combate o de despliegue. 


\section{Capacidad de concentración}

Para afrontar con éxito cualquier crisis hay que asegurar la viabilidad y eficacia de nuestras acciones. Viabilidad significa no intentar hacer aquello que no podemos hacer o es demasiado arriesgado, y eficacia es hacer aquello en lo que, sin olvidar los objetivos políticos y el principio de proporcionalidad, somos manifiestamente superiores. Para ello, es esencial concentrar en momento y lugar decisivos una fuerza superior a la del adversario. El Poder Aéreo tiene la mayor capacidad de concentración de fuerza militar en lugar y momento decisivos, proveniente de diferentes lugares del mundo en el plazo de horas, ya sea para actuar en fuerza o para ayuda humanitaria.

Todo eso sin afrontar el coste de tener los medios concentrados previamente. Alguna vez me han preguntado cómo, si existen Unidades internacionales terrestres o navales constituidas desde tiempo de paz como Eurofor o Euromarfor, no existía un «Euroairfor» o similar. La contestación es fácil: porque no hace falta. Dada la capacidad de concentración de las Fuerzas Aéreas, no se precisa constituir las Unidades desde la paz, ni entrenarlas juntas, basta con «tocar la corneta» y acudirán en pocas horas desde Alemania, Estados Unidos o España para operar ese mismo día juntos en donde se necesite, ya que en sus propias Bases están volando con sistemas de armas interoperables y utilizan los mismos procedimientos.

\section{Capacidad de penetración}

Es un resultado directo de las características fundamentales del Poder Aéreo, dominio de la altura, velocidad y alcance. Le permite operar penetrando profundamente en el dispositivo enemigo, en áreas fuera del alcance de otros medios y con alta probabilidad de supervivencia. No consiste sólo en penetrar profundamente en territorio hostil y atacar objetivos con gran precisión, sino también en la capacidad de lanzar armas o usar sensores sin entrar en zonas hostiles muy defendidas para batir objetivos o conseguir información. Es lo que se llama capacidad «stand off».

\section{Capacidad de demostración de fuerza}

La presencia de fuerzas militares es una demostración de intención o voluntad política y, como tal, es un instrumento valioso en la gestión de 
crisis. Se acepta comúnmente que la disuasión es una de las principales actividades de defensa y la más rentable de todas. La capacidad de demostración de fuerza del Poder Aéreo es un instrumento de primera magnitud para apoyo de medidas políticas o iniciativas diplomáticas, ya que sus medios pueden ser desplegados o redesplegados muy rápidamente a grandes distancias.

Su presencia puede disuadir potenciales acciones hostiles con mínimo riesgo para las fuerzas propias, ya que puede influir en la moral y voluntad de resistencia de las fuerzas contrarias. En el conflicto del Golfo, en 1991, tropas iraquíes intentaron rendirse a los vehículos aéreos no tripulados que sobrevolaban sus posiciones en misiones de corrección de tiro artillero.

\section{Capacidad de adaptación}

El Poder Aéreo tiene una notable capacidad de adaptación a toda variedad de objetivos y situaciones. De acuerdo con los cometidos asignados, puede ser decisivo ya sea destruyendo, neutralizando o incapacitando temporalmente instalaciones o sistemas. Durante la campaña aérea de Kosovo, en 1999, se neutralizó una planta de energía eléctrica en Belgrado utilizando bombas de fibras de carbono, que no pretendían destruir la instalación sino dejarla fuera de uso durante varios días.

\section{Capacidad de supervivencia}

En combate, los medios aéreos alcanzan un alto grado de supervivencia protegiéndose de distintas maneras. Las características furtivas («stealth»), derivadas de la forma del avión y de los materiales de que está compuesto o recubierto, reducen el eco radar de un gran avión al tamaño del que produciría un pájaro, haciéndolo prácticamente indetectable a las defensas enemigas. También se cuenta con la protección de las contramedidas electrónicas que embrollan las comunicaciones o radares oponentes. La capacidad stand-off de la que hemos hablado antes, permite actuar fuera del alcance de las defensas contrarias. Finalmente los aviones incorporan armas y medios de autodefensa contra aviones, misiles y demás sistemas de defensa antiaérea.

\section{Gradualidad}

Las capacidades mencionadas anteriormente, permiten a los responsables políticos de la guerra graduar la actuación en los conflictos en fun- 
ción de la situación política y militar, así como tener en cuenta un factor de creciente importancia en los mismos: la evolución de la opinión pública, tanto interior como internacional.

Desde sus posiciones en tiempo de paz, su capacidad de multirrespuesta es recuerdo permanente de la voluntad política de mantener la paz frente a cualquier agresión. La rapidez de reacción permite afrontar las amenazas de agresión inmediata, ya sea mediante demostración de fuerza o mediante despliegue preventivo, posible gracias a su movilidad. Si la intervención militar se hace indispensable, su capacidad de concentración hará efectiva rápidamente una fuerza proporcionada a la amenaza y a los fines perseguidos, y su adaptación podrá graduar la respuesta con mayor o menor intensidad, seleccionando los objetivos a batir y las armas a emplear; entonces la precisión será de capital importancia, tanto para asegurar la neutralización de las capacidades vitales del oponente, como para reducir al mínimo los daños colaterales. Un posible cambio de dispositivo, o de la actitud propia frente al conflicto, que aconseje el fin de las hostilidades y el cese de la actividad aérea, será instantáneo gracias a la flexibilidad inherente del Poder Aéreo, presente desde la constitución misma de la fuerza y en todas las fases de su empleo. Su capacidad de supervivencia, habrá hecho posible conseguir los fines políticos de la intervención militar con un mínimo de bajas y de pérdidas materiales propias. Su capacidad de ser empleado con gradualidad hace del Poder Aéreo un instrumento sumamente flexible, eficaz y rentable de acción política frente a un amplio espectro de amenazas. El mando supremo siempre podrá mantener completo control sobre él, lo que le hace idóneo para mantener bajo control cualquier crisis.

En el conflicto de Kosovo, el centro de gravedad serbio siempre estuvo al alcance del Poder Aéreo aliado: los centros de mando y control, la defensa aérea, las comunicaciones y redes de distribución, los centros de abastecimiento, depósitos de combustible y la producción de energía. Por consideraciones políticas, no se produjo un ataque masivo contra todos esos objetivos en los primeros días, y algunos, por ejemplo los puentes, nunca fueron atacados en su totalidad, mientras se atacaron unidades militares cuya destrucción no resultó necesaria, ya que se retiraron de Kosovo sin entrar en combate. Fue la decisión del mando supremo, pues el Consejo Atlántico siempre mantuvo control sobre la escalada de los ataques. Esta estrategia, que pudo alargar la campaña, tuvo la virtud de preservar el centro de gravedad de la Alianza: su cohesión. El gobierno serbio jugó la baza de resistir mientras pudo, consciente de que la cohesión de una alianza de 19 naciones con muy distintos grados de sensibilidad frente al conflicto, sometidos a un estrecho escrutinio de sus res- 
El poder aéreo, instrumento decisivo...

pectivas opiniones públicas, era su único punto débil; romperla era la única esperanza del mando serbio. Falló en sus cálculos, pues gracias a la capacidad de graduar la ofensiva con el uso del Poder Aéreo, la Alianza mantuvo el control de la escalada dentro de límites aceptables para todos sus miembros, alejando la ruptura de su cohesión (hubiera supuesto el triunfo serbio) y alcanzando la victoria, que supuso la retirada del ejército serbio, la vuelta de la población albanesa expulsada a sus hogares y la imposición del orden internacional.

Mediante la combinación adecuada de estas ventajas técnicas, políticas y operativas, el Poder Aéreo ofrece a los líderes políticos y militares la capacidad de operar eficazmente en todo el espectro de crisis o conflictos con un coste asumible y un mínimo de bajas propias.

\section{Cometidos y misiones del Poder Aéreo}

Teniendo en cuenta las características y capacidades descritas, el Poder Aéreo puede llevar a cabo, dentro del espectro completo de las operaciones militares, los cometidos y misiones que se describen a continuación.

\section{Policía del Aire (Código OTAN: Air Policing, AP)}

Es una misión permanente de las Fuerzas Aéreas, tanto en tiempo de paz como en situación de crisis. Consiste fundamentalmente en interceptar aeronaves hostiles o no identificadas que invadan el espacio aéreo propio. Los aviones interceptadores están en estado de alerta permanente y son requeridos, en el plazo de unos minutos, para obligar al avión interceptado a abandonar el espacio aéreo propio o aterrizar para inspección. Ante una acción hostil, pueden derribarlo. Dicho dispositivo de defensa aérea activa es también utilizado para ayuda o rescate de aviones civiles o militares en situación de emergencia o desastre.

\section{Defensa aérea activa (Defensive Counter Air, DCA)}

Con un carácter más general, las fuerzas aéreas son empleadas en misiones de defensa aérea activa. Consiste en la reacción de dichas fuerzas contra ataques aéreos cuando éstos se producen o pueden producirse. En ese caso, los aviones de caza y sistemas antiaéreos están en alerta, sea en el aire o en el suelo, para entrar en combate contra los medios aéreos enemigos. 
Acciones ofensivas contra el poder aéreo enemigo (Offensive Counter Air, OCA)

Suponen el uso de las fuerzas aerospaciales contra aeronaves o misiles enemigos, ya estén en tierra o en vuelo, así como contra sus infraestructuras de apoyo, bases aéreas, radares y sistemas de mando y control.

Supresión de defensas aéreas enemigas (Suppression of Enemy Air Defense, SEAD)

Consiste en neutralizar, destruir o degradar los sistemas de radares y de defensa antiaérea enemigos. Precisa de sensores y armas específicas. Es esencial para permitir la continuidad de todas las operaciones aéreas sin interrupciones ni pérdidas propias.

Los cuatro cometidos anteriores son los que permiten conseguir y mantener la superioridad aérea, descrita anteriormente y sin la cual las operaciones militares, tanto de superficie como aéreas, están condenadas al fracaso.

\section{Interdicción aérea (Air Interdicción, $\mathrm{AI}$ )}

Es una forma de actuación de las fuerzas aéreas dedicada a destruir, anular, neutralizar o degradar el potencial enemigo antes de que pueda ser usado contra las fuerzas propias. Incluye ataques a objetivos que constituyan el centro de gravedad enemigo, tratando de paralizar su capacidad de resistencia; los centros de mando y control, las comunicaciones y redes de distribución, los depósitos de combustible, armamento, centros de producción de energía, etc, son objetivos más rentables que el ataque directo a las fuerzas y producen menos bajas en la población.

\section{Apoyo directo cercano (Close Air Support, CAS)}

Consiste en el uso de los medios aéreos en apoyo directo y cercano de las fuerzas de superficie. El tipo de operación, armamento empleado y los blancos a batir tienen mucho de común con las acciones de interdicción. La diferencia más notable es que se realiza contra objetivos situados en las proximidades de las fuerzas amigas, por lo que exige una coordinación directa con las mismas. El coste de batir un blanco en estas operaciones es sensiblemente el mismo que en la interdicción, pero su rentabilidad en el contexto global de la campaña puede ser muy inferior. Por 
El poder aéreo, instrumento decisivo...

ello, las acciones CAS sólo deben ser usadas cuando las fuerzas de superficie no puedan afrontar la situación con su fuego orgánico propio.

Reconocimiento y vigilancia aéreos (Reconnaissance and Surveillance, RECCE)

Usando su característica intrínseca del dominio de la tercera dimensión, los medios aerospaciales permiten observar los diferentes teatros de operaciones tanto visual como electrónicamente. Se utilizan satélites y plataformas aéreas, tripuladas o no tripuladas, dotadas de todo el espectro de sensores (ópticos, infrarrojos, radar). Su cometido es proporcionar a los responsables políticos y militares información esencial y en tiempo útil para sus tomas de decisión, tanto en el campo estratégico como en el táctico.

Patrulla marítima y lucha antisubmarina (Maritime Patrol, MP; Antisubmarine Warfare, ASW)

Es una derivación del apoyo directo y la vigilancia aérea. Se desarrolla en ambiente marítimo y, por su especificidad, se lleva a cabo con aviones y helicópteros particularmente diseñados y equipados para esta misión.

\section{Guerra electrónica (Electronic Warfare, EW)}

El dominio del espectro electromagnético es esencial en las operaciones militares, para asegurar su libre uso por las fuerzas propias e impedir, reducir o limitar el uso por las fuerzas hostiles. Su dominio de la altura y su alcance, ofrecen a las plataformas aéreas una situación privilegiada para actuar sobre dicho espectro. El Poder Aéreo lo lleva a cabo utilizando aeronaves dotadas de sensores y equipos de radiación electromagnética. Las tres actividades que desarrollan este cometido abarcan medidas de apoyo electrónico, contramedidas electrónicas y medidas de protección electrónica (también llamadas contra-contramedidas), que cubren todo el uso ofensivo y defensivo de la capacidad de control del espectro electromagnético. El dominio de dicho espectro actúa como la superioridad aérea, dando libertad de acción y seguridad a las fuerzas propias, e impidiendo la acción ofensiva enemiga.

\section{Transporte aéreo (Airlift)}

Consiste en el transporte rápido por vía aérea de personal y carga dentro y fuera del teatro de operaciones. El transporte aéreo es una 
muestra paradigmática de la flexibilidad de los medios aéreos, pues en tiempos mínimos un mismo avión puede cambiar de misión, origen o destino y ser aplicado a distintos fines. Según su finalidad puede ser estratégico o táctico y usa tanto aviones como helicópteros. No sólo se dedica al transporte de tropas y su apoyo logístico, también es utilizado en el transporte de alimentos, medicinas y otra ayuda humanitaria, así como en operaciones de evacuación de personal en peligro, evacuaciones sanitarias u operaciones especiales.

\section{Reabastecimiento en vuelo (Air to Air Refuelling, AAR)}

Consiste en proporcionar combustible en vuelo a los aviones propios, aumentando su radio de acción, su carga útil y el tiempo de permanencia en la zona de operaciones, lo que actúa como un multiplicador de fuerza y aumenta la zona de influencia de una determinada fuerza aérea. En la campaña aérea de Kosovo, los aviones de combate españoles repostaron en vuelo una o varias veces en todas sus salidas reales.

Búsqueda y salvamento de combate (Combat Search and Rescue, CSAR)

Consiste en el rescate en territorio hostil de personal en peligro. La complejidad de esta misión, que exige una incursión con medios aéreos en territorio enemigo, conlleva mayor vulnerabilidad, e implica a fuerzas especiales, equipos de combate y de rescate. Puede precisar de helicópteros de ataque, aviones de combate y de supresión de defensas aéreas (SEAD), para proteger las aeronaves de rescate y para cubrir la acción en el momento de efectuar el rescate, sujeto a actuaciones hostiles enemigas.

\section{Misiones en apoyo de la política exterior o en situaciones catastróficas}

Gracias a su flexibilidad, las Fuerzas Aéreas utilizan sus capacidades èn misiones no específicamente militares, tanto en apoyo de la política exterior de la nación como en condiciones de desastre o de extrema urgencia, en las que dichas fuerzas actúan con mayor eficacia que otros medios. En España, entre otros servicios al Gobierno y a la sociedad, se presta un importante apoyo a la aviación civil poniendo a su disposición Bases o instalaciones aéreas militares de utilidad para el mismo. El con- 
El poder aéreo, instrumento decisivo...

trol civil de tráfico aéreo utiliza para su seguridad y fluidez las señales radar que se obtienen en los radares de defensa aérea. Igualmente se utilizan los aviones de alerta aérea permanente en apoyo de aviones civiles en situación de emergencia. Aviones militares calibran los sistemas de navegación aérea y garantizan su fiabilidad. El servicio aéreo permanente de Búsqueda y Salvamento ha salvado cientos de vidas de náufragos y accidentados o perdidos en zonas inaccesibles, muchas veces en condiciones muy críticas. Una Unidad aérea especializada en la lucha contra incendios, actúa con reconocida eficacia en toda España en cualquier momento. El Servicio Cartográfico del Ejército del Aire proporciona al Gobierno y a los particulares mapas y fotografías aéreas de interés. Aeronaves militares colaboran con la autoridad civil en la vigilancia y represión del contrabando y lucha contra la droga. Se apoya a la industria nacional en los ensayos y puesta a punto de sistemas aéreos y en sus programas internacionales. Se lleva a cabo un flexible, seguro y eficaz servicio de transporte de personalidades que incluye a las más altas del Estado. Se colabora con la Sanidad nacional en el transporte rápido e imprevisto de órganos para trasplantes. Con el ministerio del Interior en los transportes urgentes de unidades de seguridad. Con la Agencia Española de Cooperación Internacional en toda clase de misiones de ayuda humanitaria en los países más lejanos. Se han trasladado animales de especies protegidas, se ha colaborado con la Universidad en el estudio de migraciones de aves, se han atacado desde el aire vertidos de petróleo en el mar, se ha garantizado la seguridad aérea en la Olimpíada de Barcelona y otros eventos deportivos o sociales, se colabora con las organizaciones de deportes aéreos y un sin fin más de servicios prestados a la sociedad. Citaremos por último, el papel de la patrulla acrobática «Águila», que pasea la bandera española por el mundo en medio de una demostración de belleza, riesgo controlado y profesionalidad reconocida al nivel de las mejores patrullas del mundo.

\section{Consideraciones fundamentales sobre el empleo del Poder Aéreo}

A lo largo de la exposición, han venido apuntándose ciertas reflexiones sobre el uso del Poder Aéreo derivadas de sus características y capacidades. Su participación es indispensable en casi cualquier acción militar, desde las humanitarias a los más severos escenarios de guerra, por lo que deberá actuar coordinadamente con otros organismos civiles o militares. Conviene por ello recapitular y añadir algunas consideraciones sobre limitaciones, debilidades y requisitos de su empleo, cuyo conoci- 
miento resulta indispensable a los responsables políticos o militares que, por estar implicados en decisiones relacionadas con el mismo, deben saber cómo emplear el Poder Aéreo y convertirlo en un instrumento flexible y eficaz.

\section{Interacción con la política}

Es de sentido común que si, como decía Clausewitz, la guerra es la continuación de la política por otros medios, debe asegurarse el control político de la guerra en los niveles más altos de la dirección de la misma. De él deben emanar claras directivas que aseguren la cohesión entre los fines políticos a alcanzar, las hipótesis militares a adoptar, los objetivos estratégicos y los resultados deseados al cese de las hostilidades. Durante el planeamiento de la campaña aérea, a la vista de tales directivas, deben analizarse los factores estratégicos determinantes del empleo que haya de darse al Poder Aéreo. Cada alternativa debe evaluarse en términos de la capacidad del mismo para alcanzar las metas que fijen las directivas políticas, determinando al final los medios a emplear, dispositivo a adoptar, objetivos a batir en cada fase y reglas de enganche, así como las normas de coordinación con otras fuerzas participantes. La evolución de la situación durante el desarrollo de la campaña, exigirá la actualización del proceso: directivas políticas - análisis estratégico - decisión sobre el empleo del Poder Aéreo.

Durante todo el proceso, los mandos militares tienen la responsabilidad de mantener informado al mando político sobre asuntos militares, como posibles resultados de las acciones que se deciden, coste de las mismas, posibilidades y limitaciones del Poder Aéreo para el logro de los objetivos que se señalen, consecuencias militares de las distintas alternativas, posibles daños colaterales y consecuencias de las reglas de enganche. Por ejemplo, una regla de enganche "garantista», propia de tiempo de paz, que exige la identificación visual positiva de un avión hostil antes de ser autorizado a abrir fuego, aunque se haya identificado en el radar, pone en peligro al interceptador propio al ponerle a merced de los misiles enemigos, lo cual debe ser tenido en cuenta por el mando político que fija. las reglas de enganche.

\section{El control del espacio aéreo. Superioridad aérea}

El control del espacio aéreo es de vital importancia para todas las fuerzas militares, y es una de las principales contribuciones del Poder 
El poder aéreo, instrumento decisivo...

Aéreo al éxito de las operaciones en el mar y la tierra. Por ello, el primer y más intenso esfuerzo de las fuerzas aéreas debe ser dedicado a neutralizar las defensas aéreas y antiaéreas contrarias, hasta establecer una situación aérea favorable, que es aquella que hace insuficiente el esfuerzo de las fuerzas aéreas enemigas para impedir el éxito de nuestras operaciones. Más deseable es conseguir la superioridad aérea si se quiere operar con libertad de acción en momento y lugar determinados. Si lo que se pretende es una completa libertad de acción en cualquier momento y lugar se requiere la supremacía aérea, que exige la completa neutralización del dispositivo aéreo y antiaéreo del enemigo.

Ya se ha insistido anteriormente en la importancia de conseguir un cierto grado de superioridad aérea para el éxito de las operaciones, así como se ha destacado la escasa eficacia, e incluso la inutilidad del Poder Aéreo propio, si la superioridad es del adversario. Por ello debe resistirse la tentación de iniciar operaciones aéreas o terrestres de envergadura antes de haber conseguido un grado de superioridad aérea proporcionado al riesgo de nuestras operaciones.

La superioridad aérea empieza a adquirirse antes de las hostilidades, cuando una nación o una alianza crea un Poder Aéreo superior, no tanto desde el punto de vista cuantitativo como desde el cualitativo. Superior en tecnología, en organización, en información e inteligencia, en mando y control, en entrenamiento y en capacidad operativa. Ese poder alcanzará la superioridad aérea y conseguirá libertad de acción en el aire y en superficie, sin la cual no se pueden aprovechar las ventajas de las características y capacidades aerospaciales descritas, porque estarán en manos del contrario.

El control del espacio aéreo debe extenderse al uso del espacio aéreo por las fuerzas propias. La coordinación de aeronaves, misiles y vehículos aéreos no tripulados, es requisito previo para asegurar la eficacia y seguridad de las operaciones aéreas, evitando entorpecimientos e incluso «derribos amigos». Para lograrlo, debe haber una estructura única de control que garantice la acción aérea global y, en su caso, incluya el uso flexible del espacio aéreo por la aviación civil mediante la adecuada coordinación. Tal misión debe asignarse a las fuerzas aéreas, que tienen el personal, los medios y los conocimientos para llevar a cabo tal coordinación.

\section{Centralización de la dirección y descentralización de la ejecución}

La flexibilidad del Poder Aéreo sólo puede aprovecharse bajo mando centralizado. Sólo así podrá ser rápidamente empleado en diferentes te- 
atros de operaciones (nivel estratégico político-militar), diferentes campañas (nivel estratégico operativo) o en diferentes operaciones (nivel táctico). La misma flexibilidad aconseja la descentralización de la ejecución. Sólo así se obtiene en el momento de la acción el máximo provecho de los medios aéreos, de las capacidades de mando y control, y de la profesionalidad de las tripulaciones, mejor situadas para tomar decisiones fundadas en minutos o segundos.

La aplicación de este principio en las estructuras de mando conjuntas, exige una presencia de aviadores en los órganos de mando y planeamiento proporcional a la participación en las operaciones que se exija al Poder Aéreo. Sólo así se asegura su uso rápido, flexible y rentable. Cuando el protagonismo de la campaña u operación deba corresponder al Poder Aéreo, es aconsejable que el mando de la operación sea asignado a un aviador.

\section{Vulnerabilidad del Poder Aéreo}

La mayor vulnerabilidad del Poder Aéreo está en el suelo. Por ello es una considerable ventaja tener las Bases fuera del alcance de las fuerzas enemigas. Caso contrario, debe dedicarse una defensa antiaérea específica a dichas Bases, ya que serán objetivo de primera magnitud para las fuerzas enemigas, que buscan su superioridad aérea. Si nuestro Poder Aéreo es batido en el suelo, la respuesta es imposible.

El mayor enemigo del Poder Aéreo es el Poder Aéreo enemigo. De ahí que haya que insistir en la necesidad de adelantarse a sus ataques, y anular o reducir su capacidad alcanzando la superioridad aérea desde los primeros momentos de la campaña, antes de realizar el resto de las operaciones. Iraquíes y serbios perdieron la guerra cuando perdieron su poder aéreo.

Medios baratos, de fácil uso y difícil localización, como los misiles antiaéreos portátiles, son una gran amenaza para aviones muy caros y sofisticados. Hay que volar fuera de su alcance, a altura de seguridad.

Aviones de combate sin comunicaciones seguras, contramedidas electrónicas, sistemas anti-infrarrojos y demás medios de autoprotección, son tan vulnerables que no serán aceptados como aportación nacional a una coalición.

La táctica y los sistemas que ganaron la última guerra pueden perder la próxima. Hay que evolucionar con la tecnología. Todo lo que no sea el estado del arte, la mayor calidad (que no cantidad), está en inferioridad en el aire. Todo es barato en la victoria y caro en la derrota. 
El poder aéreo, instrumento decisivo...

\section{Operatividad}

La puesta en estado de eficacia del Poder Aéreo es compleja y requiere tiempo, por ello sólo las Unidades que al iniciarse las hostilidades estén perfectamente equipadas, entrenadas y apoyadas logísticamente podrán ser utilizadas en combate. En cuanto a una hipotética movilización, sólo será útil la de líneas aéreas (únicamente para transporte) e industria aeronáutica.

La acción aérea funciona en serie. Un solo piloto en un solo avión puede batir un objetivo decisivo a miles de kilómetros en medio de una noche brumosa. Pero no despegará si uno cualquiera de los cientos de personas especializadas en diferentes funciones técnicas falla en la preparación del avión, del armamento, del combustible, la información, el control, etc. El Poder Aéreo es un equipo altamente integrado y tiene que funcionar completo o no funcionará.

La variedad y dificultad de las misiones aéreas y la necesidad de responder en segundos a toda clase de situaciones en el aire, exige a las tripulaciones un alto grado de adiestramiento y un entrenamiento sistemático. La falta de horas de vuelo, además de anular la eficacia operativa, puede resultar catastrófica. Según datos del Jane's Defence Weekly de 22 de agosto, la Fuerza Aérea rusa ha pasado de 3.3 aviones perdidos por cada 100.000 horas de vuelo en 1990 (cifra equiparable a las de NATO) a 8.3 aviones por 100.000 horas. Todo lo atribuye a un descenso de las horas/piloto/año que puede llegar a 14. El mínimo fijado por el ACE Force Standard de la NATO es 180horas/piloto/año.

\section{Personal}

A pesar de la elevada tecnología, coste de los sistemas, y compleja organización propios del Poder Aéreo, la baza más decisiva, cara y difícil de mantener a punto es el personal que, con su profesionalidad, valor, dedicación y empeño, suple las carencias de los sistemas, las dificultades del entorno y la incertidumbre del planeamiento. El valor de un piloto de combate en términos de capacidad de destrucción a gran distancia, es equivalente a varios miles de hombres actuando en tierra. El coste y duración de la formación y entrenamiento de pilotos, ingenieros y especialistas es muy elevado. Su alta preparación les hace ser solicitados por líneas aéreas y otras empresas (a nivel de los medios es bien conocido el problema de la «fuga de pilotos»). El coste de su sustitución, en dinero y tiempo, hace sumamente rentable cualquier medida que favorezca su re- 
tención, y así son bastantes las naciones que, conscientes del problema, han asignado incentivos económicos importantes para evitar la sangría.

\section{Actuación en coalición}

El alto coste de constitución y operación de un Poder Aéreo con el grado de superioridad necesario, queda fuera del alcance de la mayoría de las naciones actuando individualmente. Ello, unido a consideraciones políticas racionales, ha impuesto la necesidad de actuar en coalición, tanto a la hora de producir sistemas de armas aéreos como a la de operarlos en los conflictos previsibles. Con ello se evita la dependencia y se consiguen un grado de seguridad compartida, un avance tecnológico y un beneficio económico y social imposibles de alcanzar actuando aislados.

\section{Principios de la guerra}

Lo avanzado de su tecnología y las brillantes capacidades del Poder Aéreo, de nada valen si no se mantienen los principios fundamentales de cualquier guerra, desde la primitiva de la cachiporra a la más sofisticada de las armas guiadas por láser. Nada sustituye a la voluntad de vencer, acción de conjunto y sorpresa. Es la única explicación a la derrota de Fuerzas poderosas por otras inferiores de las que hemos visto ejemplos en el último tramo del siglo XX.

\section{Conclusisones}

La indefinición que caracteriza la actual situación geoestratégica, realza el valor de la flexibilidad, rapidez de reacción, gradualidad de empleo, movilidad y polivalencia propias del Poder Aéreo. Su contribución a la arquitectura de seguridad, que exige la amenaza, es decisiva. Los responsables políticos pueden mantenerlo bajo control en tiempo casi real, por lo que puede ser aplicado gradual y proporcionadamente, cualquiera que sea la evolución de la situación política y estratégica.

El entendimiento mutuo de políticos y militares es indispensable a la hora de determinar el empleo del Poder Aéreo, teniendo en cuenta las capacidades y limitaciones del mismo, y la evaluación de las diferentes alternativas que satisfagan las directrices politicas.

La actuación en solitario del Poder Aéreo no ofrece avances sobre el terreno, ni se aprecian sus resultados hasta que se produce la victoria. 
Entretanto se destacan en los medios las víctimas de daños colaterales que, por reducidos que sean, siempre son considerados excesivos. La evolución de la opinión pública debe ser atentamente considerada como un factor más en el planeamiento y el desarrollo de las operaciones, pues puede ejercer una poderosa influencia sobre ellas.

El Poder Aéreo propio de escenarios futuros no está al alcance de naciones individuales. Las coaliciones son el único camino viable para alcanzar las capacidades necesarias, con ventajas tecnológicas, económicas y sociales en el marco de una seguridad compartida más elevada.

El Poder Aéreo alcanza su mayor eficacia cuando consigue la superioridad aérea. En situación de inferioridad puede quedar neutralizado. Una situación aérea favorable es absolutamente imprescindible para acometer operaciones terrestres, navales o aéreas.

La eficacia del Poder Aéreo se basa en la superioridad tecnológica, organizativa y operativa. Dicha superioridad se logra de hecho en el momento de constitución de la fuerza en tiempo de paz, pero debe mantener su capacidad operativa entrenándose hasta su utilización.

La acción conjunta es la única posible en el siglo XXI. Significa la acción coordinada de las distintas capacidades, integradas bajo dirección única con órganos de mando y control equilibrados, manejables y prácticos.

El Poder Aéreo es un instrumento sumamente flexible y rentable para su uso en cualquier crisis, desde las acciones humanitarias a la guerra abierta. 